\title{
One Versus Two Stages Surgery of Secondary Cheilorhinoplasty and Alveolar Cleft Grafting
}

\author{
Original Maram N. Breshah, Mohamed M. Shoushan, Abdelfattah A. Sadakah, Khaled.A. \\ Article Saad, Emad F. Essa
}

Department of Oral and Maxillofacial Surgery, Faculty of Dentistry, Tanta University, Egypt

\begin{abstract}
Purpose: This study was planned to evaluate clinically and radiographically, the outcomes of secondary cheilorhinoplasty either simultaneously with or six months after alveolar cleft grafting for patients with unilateral cleft lip nose deformity.

Materials and Methods: Interventional, comparative study carried out on twenty patients with unilateral cleft lip nose deformity, were divided randomly into two groups, group I: secondary cheilorhinoplasty was performed simultaneously with alveolar cleft grafting, group II: secondary cheilorhinoplasty was performed six months after it. Patients were assessed both clinically and radiographically.

Results: Clinically, significant improvement in functional results regarding NOSE scale and in aesthetic results of nose and lip postoperatively in both groups with no significant difference between them. Radiographically, significant improvement in the nasal airway volume and septal deviation postoperatively in both groups with no significant differences between them.

Conclusion: No significant differences clinically and radigraphically between one and two stages surgery. Standardized photographs are efficient and can be used for aesthetic evaluation of nose and lip. CBCT and computer software are reliable tools for measuring nasal airway volume and septal deviation for assessment of nasal obsruction. NOSE scale is a reliable tool for nasal function evaluation and POSAS is an efficient tool for scar assessment.
\end{abstract}

Key Words: Alveolar cleft grafting, secondary cheilorhinoplasty, secondary cleft lip nose deformity

Received: 20 October 2020, Accepted:

Corresponding Author: Maram N. Breshah, Department of Oral and Maxillofacial Surgery, Faculty of Dentistry, Tanta University, Egypt, Tel.: +201004991193, E-mail: maram_nashaat@yahoo.com

ISSN: 2090-097X, July 2020, Vol. 11, No. 3

\section{INTRODUCTION}

Unilateral cleft lip-nose deformities represent a stigma of the cleft lip nose patient. This results from a combination of surgical scarring from previous reconstructive attempts, altered anatomy, and the inevitable effects of growth ${ }^{[1,2]}$. It includes deformities of the septum, nasal pyramid, malformation of the nasal tip and malposition of ala on the cleft side and the severity of the deformity varies with each case and is directly related to the extent of the lip deformity and particularly the alveolar cleft. The maxillary cleft along with hypoplasia and malpositioning of the maxillary segments also contribute significantly to the facial asymmetry ${ }^{[3]}$.

The deformities characterized by distal, downward, and backward dislocation of the skeletal framework which causes all components of the lip and nasal tissue to be malpositioned three-dimensionally on the affected side consequently, the upper and lower lateral cartilages dislocate distally and downwardly. Additionally, excessive stress over the nasal tip and dorsum causes growth disturbances of the septal cartilage, resulting in a short columella and flared nasal tip on the affected side ${ }^{[4]}$.
Definitive rhinoplasty is performed after the completion of maxillary and nasal growth between 14-16 years of age. At this time, rhinoplasty is definitive in that more aggressive septoplasty, osteotomies, and cartilage grafting maneuvers may be performed without concerns for affecting nasal and midfacial growth ${ }^{[2]}$.

Large number of cleft lip and palate patients missed the alveolar cleft grafting procedure during the long course of treatment and rehabilitation of the cleft deformities and their late presentation should not be refusal criteria as recommended by Mahajan et al, $2017^{[5]}$ to provide a platform for the dental implant placement, orthodontic movement of the teeth, improvement in the soft tissue symmetry and aesthetics of the nose. Other patients presented with inadequately repaired alveolar cleft. This was suitable to combine it with the definitive rhinoplasty procedure which indicated after complete growth of the nasal structure either simultaneously or six months before rhinoplasty.

Alveolar bone graft provides certain redeeming bone support for the nose and thus beneficial for secondary cleft nasal deformity correction ${ }^{[6,7]}$. Positive effects of bone 
graft on facial or nasal symmetry have been shown in several studies, which supports its performance along with secondary rhinoplasty ${ }^{[8,9]}$.

Mokal and prabhash, $2009^{[8]}$ found that simultaneous alveolar bone grafting can be combined with secondary unilateral cleft lip rhinoplasty safely and effectively as it provides an aesthetically pleasing nose and improves symmetry without any additional morbidity.

On the other hand, Wu et al, 2010 ${ }^{[10]}$ in his study showed that the nasal profile appears worse after alveolar bone grafting operation as the nostril tends to appear more flat. The study also indicated that parts of the grafting bone will be absorbed, and the nasal profile may change after operation, especially 6 months later. Therefore, it is not recommended that rhinoplasty and alveolar bone grafting be applied at the same time.

However, Kim et al, 2016 $6^{[11]}$ showed that simultaneous cleft lip rhinoplasty during alveolar bone grafting improves the nasal profile especially in adolescents ameliorating the unfavorable effects of peri-alar augmentation, and the improvement is maintained during long-term follow-up. Therefore, patient's distress from cleft lip nasal deformity and the number of additional operations were reduced.

Accordingly, this study was planned to evaluate the achieved results clinically and radiographically following one versus two stages surgery of secondary cheilorhinoplasty and alveolar cleft grafting.

\section{PATIENTS AND METHODS}

Twenty patients aged between fifteen and thirty years old, with unilateral non repaired secondary cleft lip-nose deformity and non-repaired or inadequately repaired alveolar cleft included in this study and divided randomly into two equal groups (10 patients each). The patients and their parents signed the written consents to participate in this study. Approval for this study was obtained from Research Ethics Committee (REC), Faculty of Dentistry, Tanta University.

After collecting demographic data, chief complaint, history of previous surgeries, full clinical examination had been carried out including complete extraoral and intraoral clinical examination followed by filling of the Nasal Obstruction Symptom Evaluation (NOSE) questionnaire for functional evaluation of the nose according to Stewart et al, 2004 ${ }^{[12]}$, then photographic documentation using standard photographic frontal, profile and submental views ${ }^{[13]}$ for aesthetic evaluation of the nose and lip (Alar inclination angle (AIA) ${ }^{[14]}$, Nasolabial angle (NLA) $)^{[15]}$ normally between $95^{\circ}$ and $105^{\circ}$, Nasofacial angle (NFA) ${ }^{[16]} 36^{\circ}$ with a range of 30 to $40^{\circ}$, Alar base distance ${ }^{[17]}$ when right side equal to left side, symmetry was considered excellent, Ala-tip angle ${ }^{[17]}$. When the angles are equal, it was excellent, upper lip height ${ }^{[18]}$, the proportion index is the ratio of the cleft side to the non-cleft side, Figure 1 and scar assessment by Patient and Observer Scar Assessment Scales (POSAS) ${ }^{[19]}$.

Radiographic examination including, panoramic radiograph used for evaluation of the alveolar cleft area regarding the site of cleft in relation to teeth. The relation of neighboring teeth either impacted, malposed, retained deciduous, missing or deformed teeth and presence of any pathological condition related to the cleft site or the donor site in mandible.

Cone beam computed tomography (CBCT) scan used for evaluation of the morphology, the size of the cleft side and the deficiency of the pyriform margin in relation to the alar base. CBCT images were analyzed using 3-dimensional imaging software. Nasal airway volume measurements in both sides were collected using an integrated volumetric measurement tool, septal deviation was measured from the midline in the coronal Plane ${ }^{[20]}$, Figures 2 and 3.

Surgical procedure: The alveolar cleft repair was achieved firstly for both groups.

Alveolar cleft repair: The procedure was started with turn over flap for the alveolar cleft repair. Incisions were made along the alveolar cleft margins and gingivoperiosteal flaps were raised along the nasal and labial surfaces. The nasal floor was repaired using nasal mucoperiosteal lining along the pyriform margin. Palatal gingivoperiosteal layers are sutured together to complete the oral lining. Autogenous cortico-cancellous bone graft was obtained from the chin bone or the anterior iliac crest. The autogenous bone graft was packed in the three- dimensional bony defect in the alveolus and extended along the pyriform margin below the alar base to aid in supporting it. The cortico-cancellous bone graft was snugly fitted in all patients except two cases was fixed with mini plate and screws. A water-tight mucoperiosteal closure was achieved using 40/ polyglactin suture and tight closure in layers of the donor site of bone graft either from the chin or the anterior iliac crest, Figure 4. 


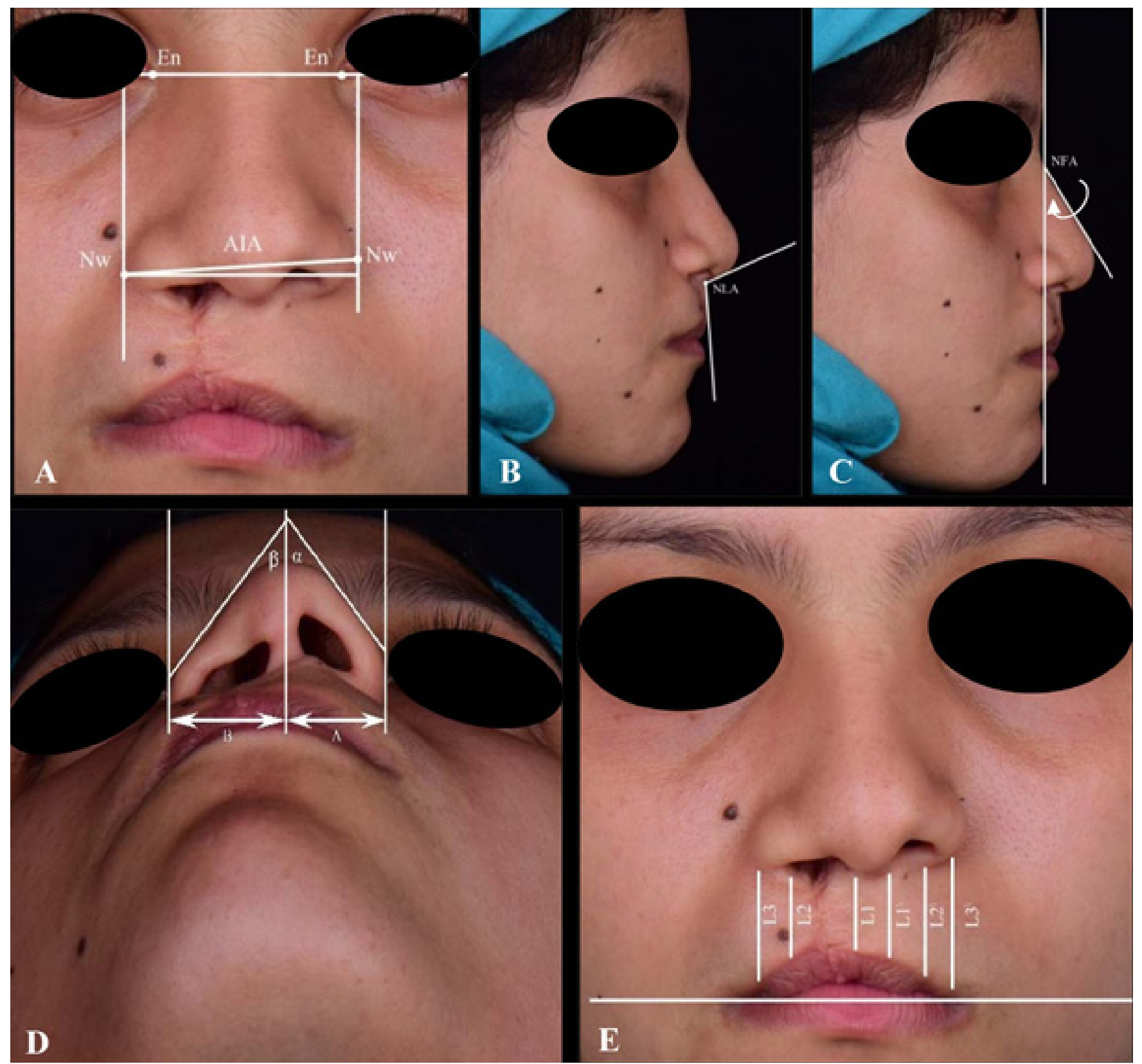

Fig. 1: Preoperative photographs (Frontal, profile and Submental views) of patient No. (2), Group (II) showing: A) Alar Inclination angle (AIA), B) Nasolabial angle (NLA), C) Nasofacial angle (NFA), D) Ala tip angles and alar base distances and E) L1, L2, L3 for height of upper lip. 
Bershah et al.
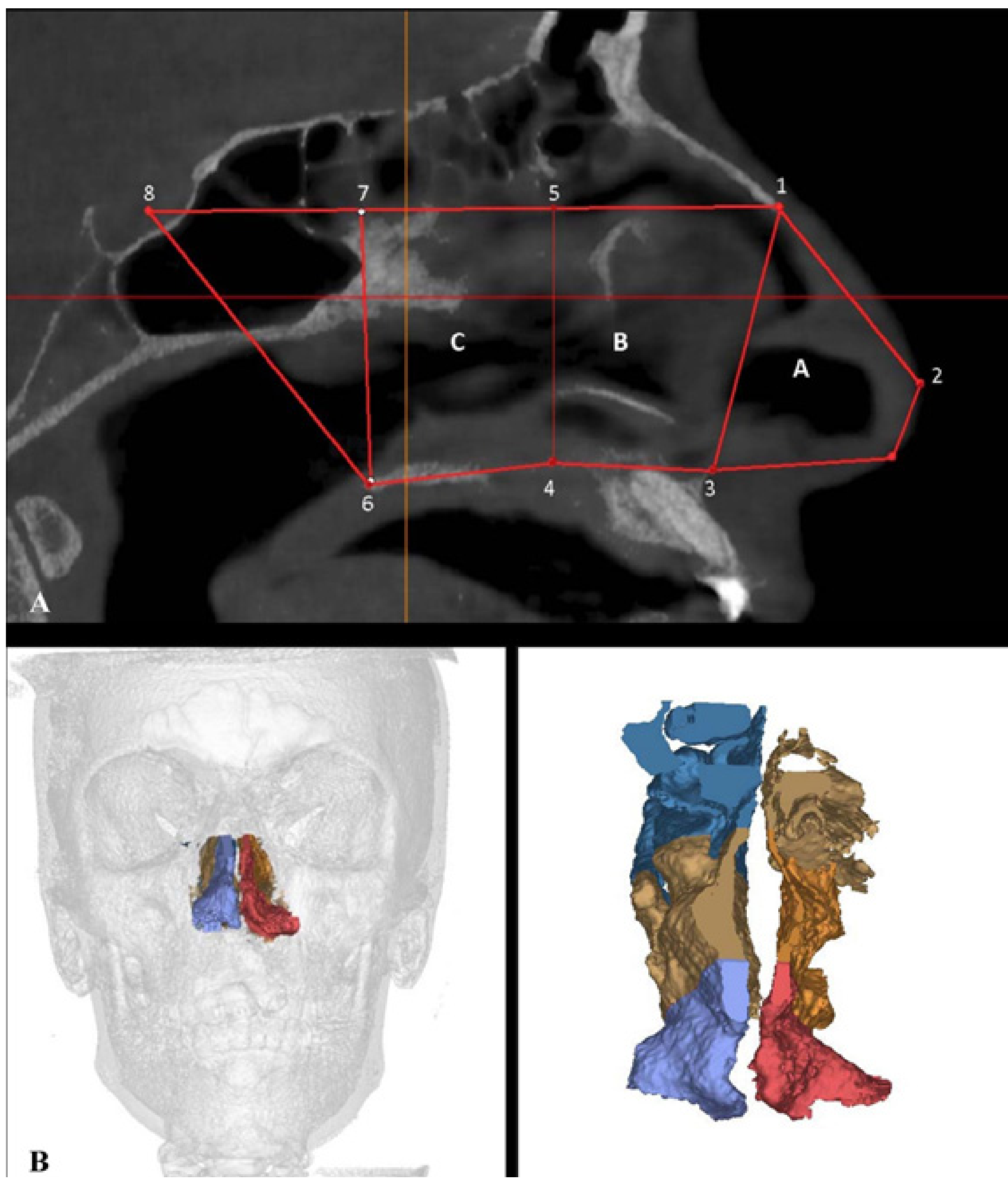

Fig. 2 : A) Preoperative photoradiograph of sagittal CBCT scan showing three areas of volumetric analysis of the nasal airway (A, B, C) of case No. (1), Group (I). 1) is Rhinon, 2) is soft tissue pronasale, 3) is anterior nasal spine(ANS), 4) is midpoint between the ANS and PNS, 5) is a constructed landmark denoting the intersection of a perpendicular line from midpoint and line drawn through rhinon-sella turcica, 6) is posterior nasal spine(PNS), 7) is intersection of rhinon-sella turcica and perpendicular line through PNS, 8) is sella turcica. B) 3D CBCT and three-dimensional model of right and left nasal airway of case No. (5), Group (I) 


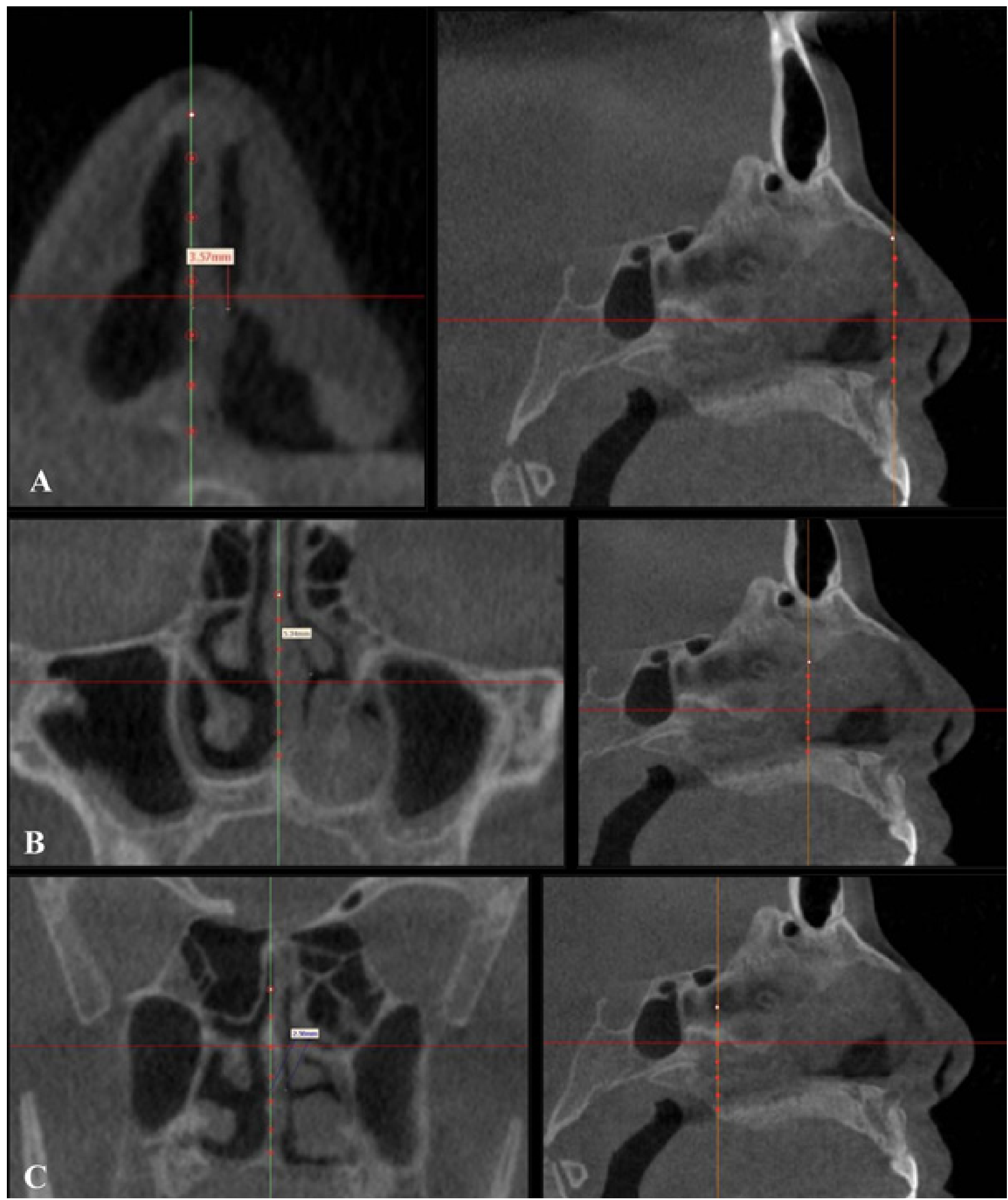

Fig. 3: Septal deviation from the midline (green line) in coronal view was measured after setting the sagittal plane through the A) ANS, B) midpoint between anterior and PNS and C) PNS in sagittal view(red line) of case No. (5), Group (I). 


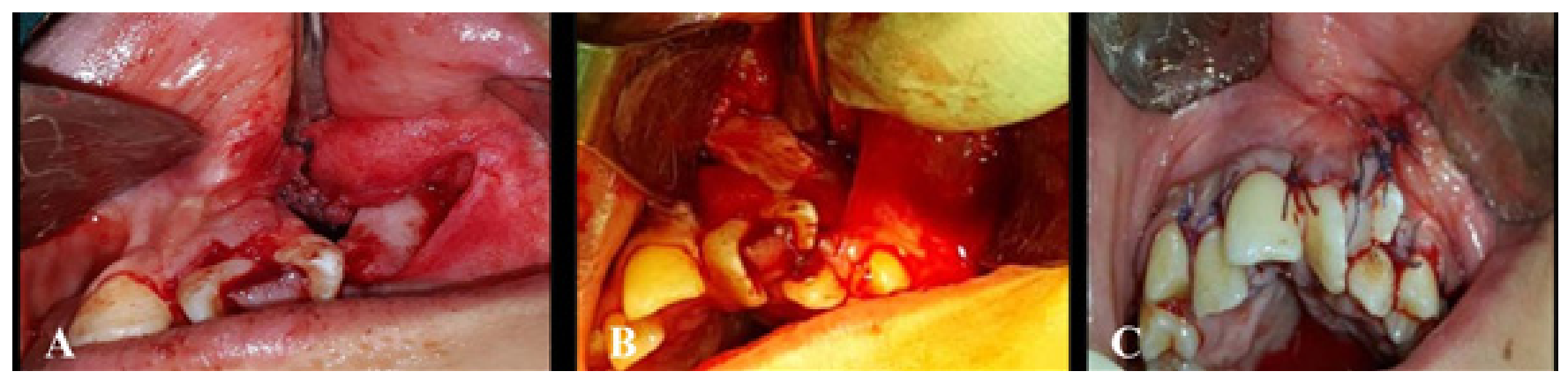

Fig. 4: A) Intraoperative photograph showing alveolar cleft grafting, , B) placement of snugly fitted bone graft in the alveolar cleft defect and $\mathrm{C}$ ) closure with buccal sliding flap and transition of the distal papilla.

For patients in group I secondary cheilorhinoplasty was performed simultaneously with alveolar cleft grafting in the same operation, while for patients in group II we waited for six months then, secondary cheilorhinoplasty was performed in another operation.

Cheilorhinoplasty: Open rhinoplasty was applied according to Nolst-Trenité, 2005 ${ }^{[21]}$ through a transcolumellar incision connected to marginal reverse- $\mathrm{U}$ incision following the caudal border of the lower lateral cartilage. the malpositioned lower lateral alar cartilage was exposed from the nasal skin and the distal ends of the lateral crura was freed from the surrounding tissue. The interdomal ligament between the medial crura was divided to access the caudal septum, then a small, square cartilaginous strut approximately $8-10 \mathrm{~mm} \times 15 \mathrm{~mm}$ was taken from the lower part of the nasal septum and transferred to the anterior edge of the nasal septum and used as columellar strut or onlay graft over the reduced alar cartilage. The medial crus of the lower lateral cartilage on the affected side was repositioned and fixed symmetrically to the columellar strut using 4/0 polypropylene thread. Additional inter-domal stitches were passed between the two alar cartilages and the cartilage graft to produce appropriate tip projection. Asymmetry of the nostril size was assessed and a medial $\mathrm{Y}-\mathrm{V}$ advancement of the alar base or Z-plasty were done if indicated either alone or along with an alar cinch stitch on cleft side to narrow the nostril to achieve symmetry with the opposite side.

Notching or mismatch at the vermillion-cutaneous junction was corrected by realignment, small triangular flaps, or a Z plasty . A poorly defined tubercle was corrected by V-Y advancement. Correction of a prominent scar with inadequate lip length and compromised muscle function required a full thickness revision.

The open rhinoplasty incisions were then sutured with 5-0 polyproplyne suture. Modified intranasal stent was used. Sterile paper tapes will be applied over the dorsum to facilitate the re-draping of the skin envelope to the cartilaginous framework, Figure 5.

The routine postoperative care including antibiotics, non-steroidal anti-inflammatory drug, nasal decongestant drops and patients were instructed to avoid negative or positive pressure inside the nasal cavity such as oral or nasal blowing and to maintain oral hygiene with mouth wash and teeth brushing. Soft diet was instructed postoperatively for two weeks. Patients came for removal of the skin sutures after 7 days of surgery but leaving the nasal stent in place from 3 to 4 weeks.

Patients were followed up clinically and radiographically for 1 year postoperatively. Clinically for healing of the graft site, presence of inflammation, infection, wound dehiscence, recurrence of oronasal fistula and graft exposure, functional evaluation of the nose by NOSE scale, aesthetic evaluation of the nose with the aid of standardized photographs for AIA, NLA, NFA, alar base distance and alar tip angle, aesthetic evaluation of the lip through upper lip height and scar assessment. Radiographically for graft incorporation, nasal airway volume and septal deviation $\left(1^{\text {st }}, 6^{\text {th }}\right.$ and $12^{\text {th }}$ month postoperatively).

Statistical analysis was performed using statistical package for social sciences (SPSS version 25). P value was calculated and data was collected and tabulated. 


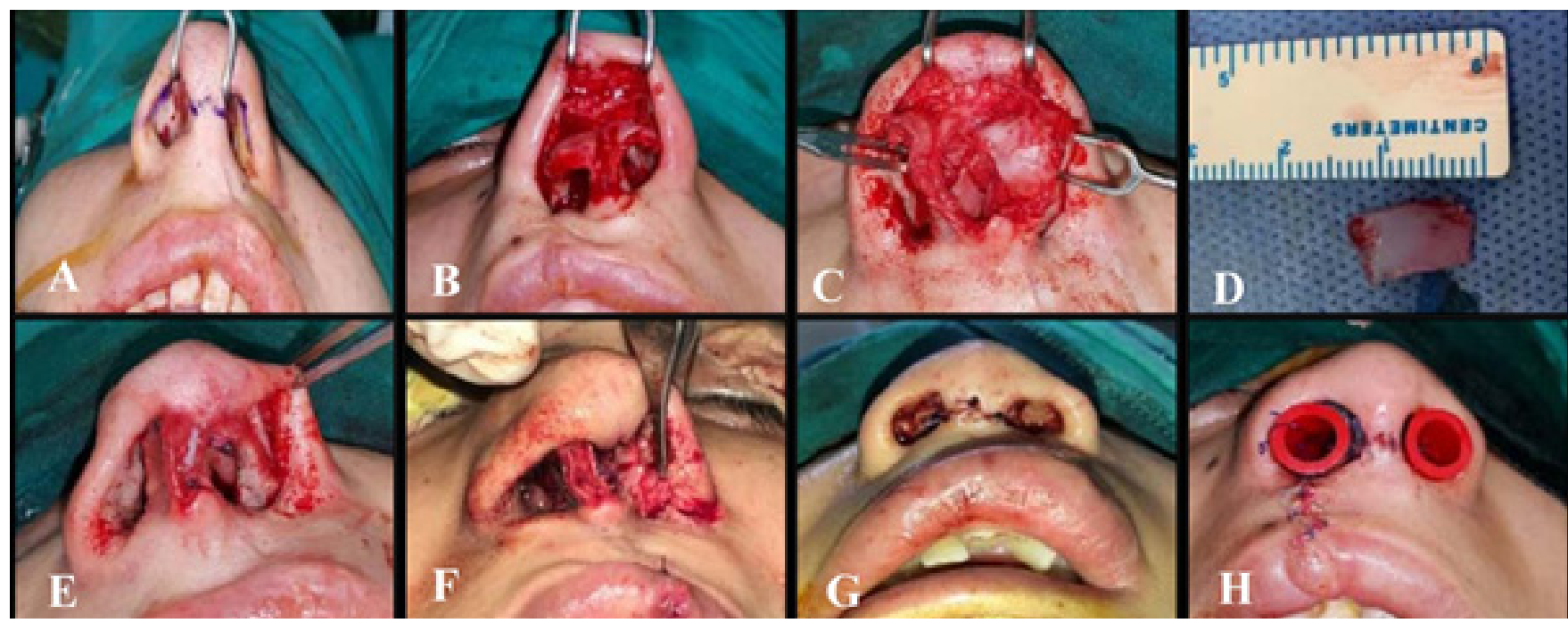

Fig. 5: Intraoperative photographs of cheilorhinoplasty: A) Marking of transcolumellar incision with bilateral reverse-U incision, B) Open rhinoplasty showing asymmetry of lower lateral catilages, C) Division of the interdomal ligament to access the caudal septum, D) Septal cartilage graft about $1 \times 1.5 \mathrm{~cm}$, E) Suturing of the columellar strut and onlay cartilage graft, F) Triangles of Z-advancement for medialization of laterally displaced alar base of cleft side, G) Suturing of the skin incision with 5/0 polyproplyene, H) Repair of upper lip and realignement of vermillion-cutaneous junction, two catheter tube ends inside the nostrils as nasal stent

\section{RESULTS}

Clinically : the wound healing process was progressed uneventfully in both groups without major complication. Patient No. (2), group (I), which showed wound dehiscence with mild inflammation, graft and plate exposure at recipient and donor site. Patient No. (1) group (I), showed severe dehiscence with mild inflammation at donor site.

This necessitate mouth wash and oral hygiene measures, at first month postoperative inflammation and wound dehiscence disappeared with formation of granulation tissue coverage at dehiscence site.

For functional evaluation of the nose: (NOSE) scale: Group (I), the mean Nasal Obstruction Symptom Evaluation (NOSE) scale of the preoperative records was 79 while that for the one-year postoperative records was 36.50. Group (II), also the mean NOSE scale of the preoperative and 6 months after alveolar cleft grafting records was 79.50 as there was no significant difference between them ( $P$ value 1.000) while the one-year post cheilorhinoplasty records was 36.90 . there was significant improvement of the nasal function of patients in both groups postoperatively ( $P$ value 0.000$)$. In comparing the function of the nose between both groups, the difference and the mean of difference between pre and postoperative values were statistically non-significant ( $P$ value 0.901$)$ $(P$ value 1.000) respectively, Table 1. For aesthetic evaluation of the nose and lip, Figures 6, 7 and 8.

Alar inclination angle (AIA): Group (I), the mean value of AIA of the preoperative records was 3.60 degree while for the one-year postoperative value was 2.07 degree, comparing the results statistically indicated highly significant difference between the one-year postoperative records along follow up period and preoperative records (P. value 0.000). Group (II), the mean value of AIA of the preoperative records was 3.08 degree and at six months after alveolar cleft grafting was 2.85 degree while for the one-year post cheilorhinoplasty value was 1.96 degree. There was highly significant difference between the one year postoperative records along follow up period and preoperative records ( $P$. value 0.000), comparing the results statistically indicated highly significant difference between the one year post cheilorhinoplasty records along follow up period and preoperative records (P. value 0.000) and between the records of six months post alveolar cleft grafting and that of preoperative records ( $P$ value 0.000). This indicating decrease of nasal asymmetry in both groups. Highly significant difference between postoperative records of one month post alveolar cleft grafting and that of preoperative $(P$ value 0.000$)$ which means that the alveolar cleft grafting decrease AIA and decrease nasal asymmetry while, there was a high significant difference between postoperative records of one month (mean value was 2.55 degree) and at six months post alveolar cleft grafting (mean value was 2.85 degree) $(P$ value 0.000) which means increase in AIA that may be due to partial graft resorption and highly significant difference between postoperative records of six months post alveolar cleft grafting and that of one year post cheilorhinoplasty ( $P$ value 0.000$)$ which means more decrease of AIA and nasal asymmetry after nasal surgery. However, the difference between both groups were statistically non-significant ( $P$ value 0.750$)$ (Table 1$)$. 


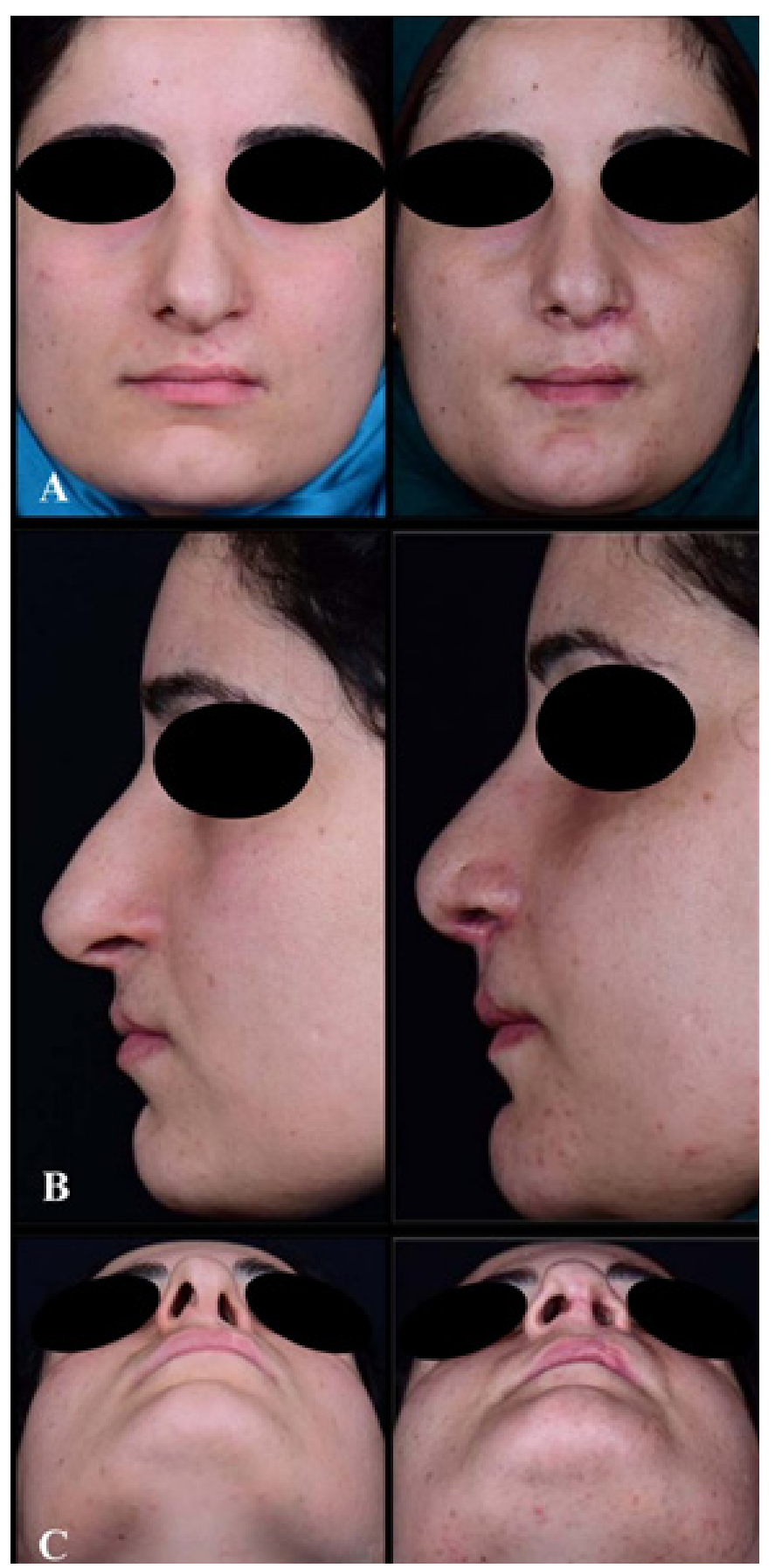

Fig. 6: A) Frontal, B) Profile and C) submental Preoperative, one month postoperative photographs of patient No. (1), Group (I) showing improvement of AIA with elevation of the nasal tip, augmentation of the nasal ala, improvement of nasolabial and nasofacial angles with increase in nasal projection, improvement in nasal symmetry, decrease in the difference between ala- tip angle and alar base distance between normal and cleft side which means elevation of nasal dome and medial advancement of alar base of cleft side. 


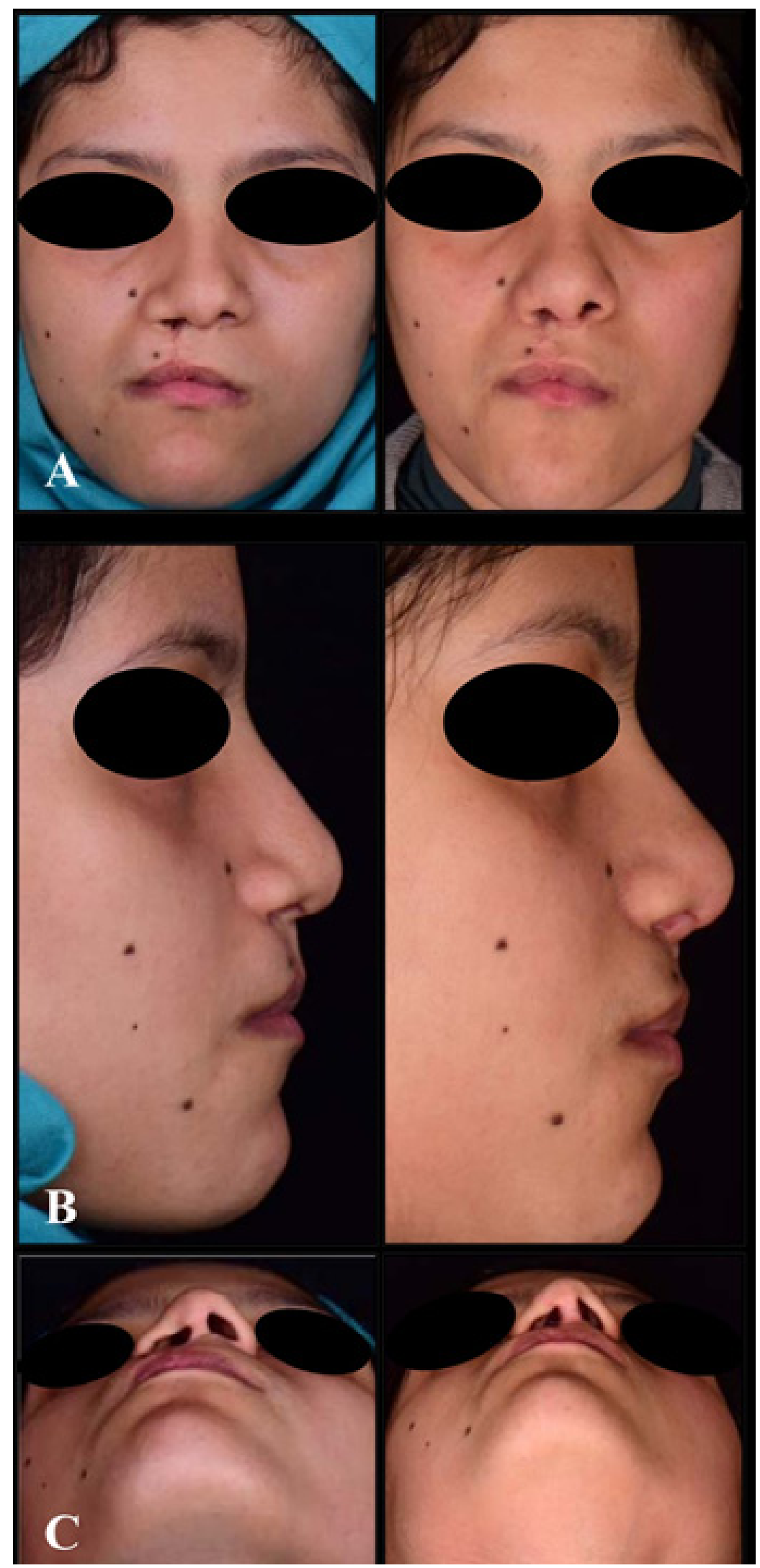

Fig.7 : A) Frontal, B) Profile and C) submental Preoperative, one year postoperative photographs of patient No. (2), Group(II) showing elevation of nasal dome, improved nasal tip, continuity of nasal sill, scar revision of upper lip with reconstruction of its contour and realignment of vermillion-cutaneous junction, improvement of NLA and NFA increasing the nasal projection and columellar show, scar revision and continuity of muscular contour of upper lip, decrease of difference of ala-tip angles with decrease of alar base distance between normal and cleft side which means elevation of nasal tip, alar medialisation of on cleft side, improved length and deviation of columella and narrowing of wide nostril on cleft side achieving nasal symmetry. 


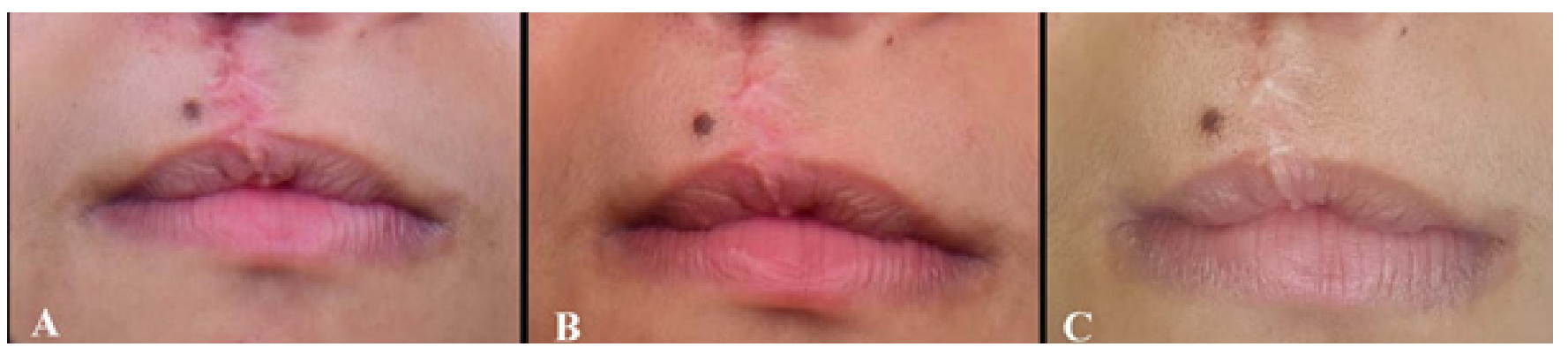

Fig. 8: A) One month postoperative photograph of patient No. 2, Group II showing thicker and expanded scar with increased vascularization, B) 6 months postoperative photograph showing decrease in thickness, expansion and vascularization of scar and C) one year postoperative photograph showing pale, thinner and contracted scar

Table 1: Statistical analysis of the nose scale alar inclination angle, alar base distance and ala tip angle between both groups postoperatively

\begin{tabular}{|c|c|c|c|c|}
\hline One year postoperative & Mean \pm S.D & Min-Max & $\mathrm{T}$ & $p$-value \\
\hline Group I & $36.50 \pm 7.09$ & $25-45$ & \multirow{3}{*}{0.126} & \multirow{3}{*}{0.901} \\
\hline & & & & \\
\hline Group II & $36.90 \pm 7.11$ & $25-45$ & & \\
\hline One year postoperatively & Mean \pm S.D & Min -Max & $\mathrm{T}$ & p-value \\
\hline Group I & $2.07 \pm 0.80$ & $1-4$ & \multirow{3}{*}{0.323} & \multirow{3}{*}{0.750} \\
\hline & & & & \\
\hline Group II & $1.96 \pm 0.72$ & $1-3$ & & \\
\hline One year postoperative & Mean \pm S.D & Min-Max & $\mathrm{T}$ & $p$-value \\
\hline Group I & $0.62 \pm 0.81$ & $0-2.30$ & \multirow{3}{*}{0.224} & \multirow{3}{*}{0.826} \\
\hline & & & & \\
\hline Group II & $0.70 \pm 0.79$ & $0-2.20$ & & \\
\hline One year postoperative & Mean \pm S.D & Min-Max & $\mathrm{T}$ & p-value \\
\hline Group I & $2.42 \pm 1.19$ & $1.50-5.50$ & \multirow{3}{*}{0.312} & \multirow{3}{*}{0.759} \\
\hline & & & & \\
\hline Group II & $2.27 \pm 0.95$ & $1.20-4.50$ & & \\
\hline
\end{tabular}


Nasolabial angle (NLA) : Group (I), the mean value of the preoperative records was 82.88 degree, while that of the one-year postoperative records was 96.10 degree. Group (II), the mean value of the preoperative records was 89.39 degree and that of 6 months post alveolar cleft grafting was 89.43 degree as there was no significant difference between them ( $P$ value 0.239), while that of the one-year post cheilorhinoplasty records was 99.62 degree.

There was a significant difference between the post and preoperative records in both groups ( $P$ value 0.004$)$ $(P$ value 0.009$)$ respectively which means improvement of NLA in both groups. However, the difference between both groups was statistically non-significant (P value 0.324) (Table 2).
Nasofacial angle (NFA): Group (I), the mean value of preoperative records was (31.37 degree) and that of one year postoperative records was (34.18 degree). Group (II), the mean value of the preoperative records was $(30.48$ degree), that of 6 months post alveolar cleft grafting was (30.49 degree) and that of one year post cheilorhinoplasty records was (33.99 degree).

There was a significant difference between postoperative records along follow up periods and preoperative records in both groups ( $P$ value 0.019) ( $P$ value 0.000$)$ respectively which indicates improvement in NFA.

However, the difference between both groups was nonsignificant ( $P$ value 0.876) (Table 2).

Table 2: Statistical analysis of photographic nasolabial and nasofacial angle between both groups postoperatively

\begin{tabular}{|c|c|c|c|c|}
\hline \multicolumn{5}{|c|}{ Nasolabial angle } \\
\hline One year postoperative & Mean \pm S.D & Min -Max & $\mathrm{T}$ & p-value \\
\hline \multirow[t]{2}{*}{ Group I } & $96.10 \pm 8.02$ & $85-110$ & \multirow{4}{*}{1.015} & \multirow{4}{*}{0.324} \\
\hline & & & & \\
\hline \multirow[t]{2}{*}{ Group II } & $99.62 \pm 7.48$ & $84.90-110$ & & \\
\hline & \multicolumn{2}{|c|}{ Nasofacial angle } & & \\
\hline One year postoperative & Mean \pm S.D & Min -Max & $\mathrm{T}$ & p-value \\
\hline \multirow[t]{2}{*}{ Group I } & $34.18 \pm 3.33$ & $29.70-40$ & \multirow{3}{*}{0.159} & \multirow{3}{*}{0.876} \\
\hline & & & & \\
\hline Group II & $33.99 \pm 1.81$ & $31-37.20$ & & \\
\hline
\end{tabular}

There is a significance at $P$-value $<0.05$

Alar base distance: Group (I), the mean value of the preoperative records was $(2.17 \mathrm{~mm})$ and that of the one-year postoperative records was $(0.62 \mathrm{~mm})$. Group (II), the mean value of the preoperative and 6 months post alveolar cleft grafting records was $(2.26 \mathrm{~mm})$ as there was no significant difference between them ( $P$ value 1.000$)$ and that of the one-year post cheilorhinoplasty records was $(0.70 \mathrm{~mm})$. There was highly significant difference between the postoperative records along follow up periods and preoperative records in both groups $(P$ value 0.000$)$ which indicating decrease of the alar base difference. However, the difference between both groups was statistically non-significant ( $P$ value 0.826$)$ (Table 1$)$.

Ala-tip angle: Group (I), the mean value of the preoperative records was (5.96 degree) while that of the one-year postoperative records was (2.42 degree). Group (II), the mean value of the preoperative records was (5.88 degree) and that of six month post alveolar cleft grafting was (5.34 degree) with no significant difference between them $(P$ value 0.198$)$ and that of one-year post cheilorhinoplasty records was (2.27 degree). There was a highly significant difference between the one year postoperative and preoperative records in both groups $(P$ value 0.000$)$. However, the difference between both groups was statistically non-significant $(P$ value 0.759$)$ (Table 1).

Upper lip height: For L1/L1 $\backslash$ proportion index, there was significant difference between the one-year post and preoperative results in both groups ( $P$ value 0.012$)$ $(P$ value 0.002$)$ respectively. For $\mathrm{L} 2 / \mathrm{L} 2 \backslash$ proportion index, there was no statistically significant difference between the one-year post and preoperative results in both groups ( $P$ value 0.592$)$ ( $P$ value 0.129$)$ respectively. For $\mathrm{L} 3 / \mathrm{L} 3 \backslash$ proportion index there was no statistically significant difference between the one-year post and preoperative results in both groups ( $p$ value 0.124) $(P$ value 0.085$)$ respectively. Postoperative values of $\mathrm{L} 1 / \mathrm{L} 1 \backslash, \mathrm{L} 2 / \mathrm{L} 2 \backslash$ and $\mathrm{L} 3 / \mathrm{L} 3 \backslash$ were closer to 1 than preoperative values indicate increase symmetry of upper lip. However, the difference between both groups was not significant ( $P$ value for $\mathrm{L} 1 / \mathrm{L} 1 \backslash 0.631$, for $\mathrm{L} 2 / \mathrm{L} 2 \backslash 0.457$ and for L3/L3\0.840), Table (3). 
Table 3: Statistical analysis of proportion indices of upper lip between both groups postoperatively

\begin{tabular}{|c|c|c|c|c|}
\hline & & $\mathrm{L} 1 / \mathrm{L} 1 \backslash$ & & \\
\hline One year postoperative & Mean \pm S.D & Min -Max & $\mathrm{T}$ & p-value \\
\hline \multirow[t]{2}{*}{ Group I } & $0.963 \pm 0.05$ & $0.83-1.01$ & & \\
\hline & & & 0.488 & 0.631 \\
\hline \multirow[t]{2}{*}{ Group II } & $0.954 \pm 0.03$ & $0.90-0.99$ & & \\
\hline & & $\mathrm{L} 2 / \mathrm{L} 2 \backslash$ & & \\
\hline One year postoperative & Mean \pm S.D & Min -Max & $\mathrm{T}$ & $p$-value \\
\hline \multirow[t]{2}{*}{ Group I } & $0.961 \pm 0.06$ & $0.87-1.01$ & & \\
\hline & & & 0.760 & 0.457 \\
\hline \multirow[t]{2}{*}{ Group II } & $0.969 \pm 0.05$ & $0.84-1$ & & \\
\hline & & $\mathrm{L} 3 / \mathrm{L} 3 \backslash$ & & \\
\hline One year postoperative & Mean \pm S.D & Min -Max & $\mathrm{T}$ & $p$-value \\
\hline \multirow[t]{2}{*}{ Group I } & $0.975 \pm 0.07$ & $0.88-1.10$ & & \\
\hline & & & 0.253 & 0.840 \\
\hline Group II & $0.981 \pm 0.01$ & $0.90-0.99$ & & \\
\hline
\end{tabular}

Patient and observer scar assessment scale (POSAS): It was noted that there was an improvement of the scar postoperatively than preoperatively and the overall patient score was lower than the observer score (Figures 9 and 10).

\section{Radiographically: Site of alveolar cleft grafting:} All cases showed integration of bone graft radiographically with the surrounding bone at the alveolar cleft site except case no. 4 group I ( $5 \%$ ) which showed failure of integration and resorption of bone graft (Figure 11).

Nasal airway volume: There was a highly significant difference between the postoperative results at ANS $(P$ value 0.000) ( $P$ value 0.000$)$ and preoperative values and significant difference between that at midpoint
( $P$ value 0.015) (P value 0.014) and preoperative values and no significant difference between that at PNS and preoperative values ( $P$ value 1.000$)(P$ value 0.343$)$ in both groups respectively, which indicates improvement of the nasal airway volume at ANS and midpoint between ANS and PNS and no improvement at PNS.

The difference between both groups one year postoperatively was statistically non-significant in the cleft side $(P$ value 0.105$)$ and non-cleft side $(P$ value 0.682$)$ (Table 4).

Septal deviation: there was improvement in septal deviation at ANS and midpoint between ANS and PNS and no improvement at PNS in both groups with no significant difference between both groups $(P$ value at ANS 0.727, at midpoint 0.417 and at PNS 0.793) (Table 5). 


\section{Patient and observer assessment scale at group I}

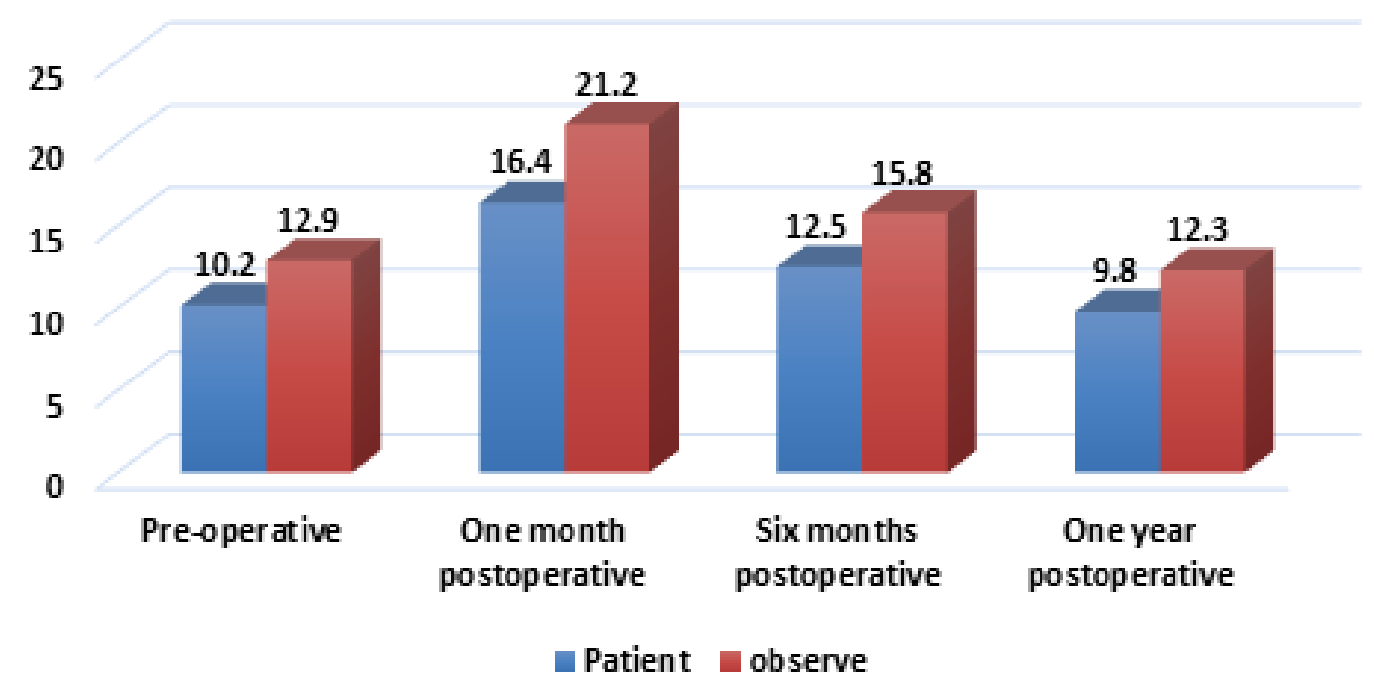

Fig. 9: Bar graph showing the mean value of Patient and observer scar assessment scale along follow up periods in group I.

\section{Patient and observer assessment scale at group II}

25

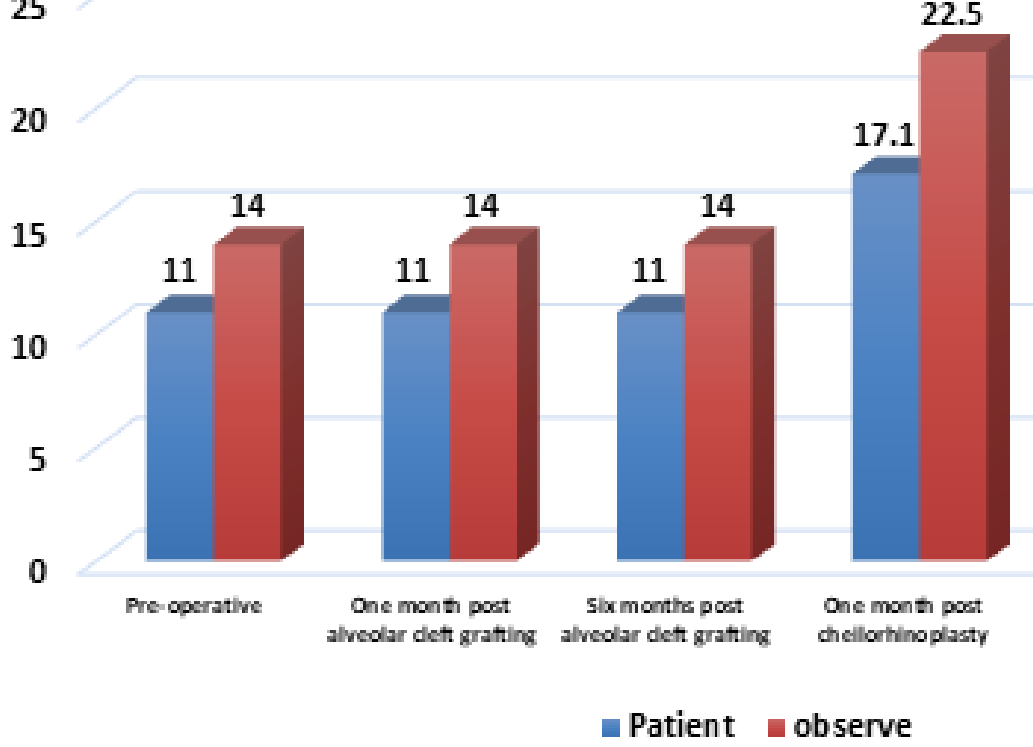

16.4

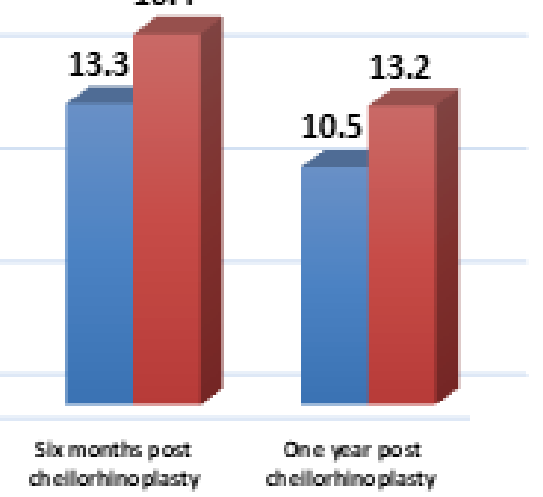

chellorhino plasty chellorhinoplasty

Fig. 10: Bar graph showing the mean value of Patient and observer scar assessment scale along follow up periods in group II. 


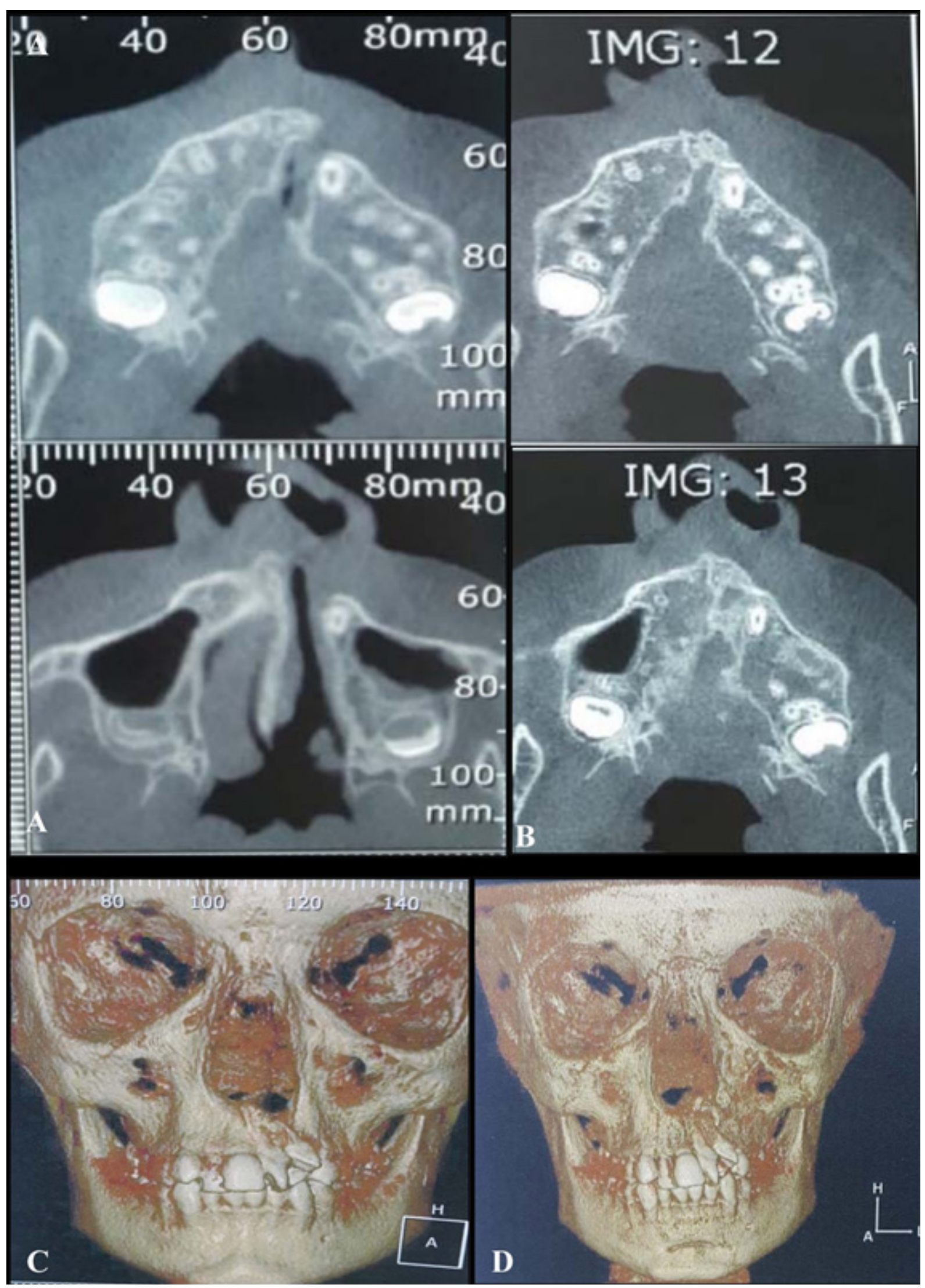

Fig. 11: Photoradiograph of A) preoperative, B) six months postoperative axial CBCT showing integration of bone graft and formation of bone bridging the gap of the alveolar cleft that elevate the alar base of the nose of case No. 1, Group II.

C) preoperative, D) six months postoperative 3D CBCT scan showing augmentation of the pyriform margin of case No. 1, Group II. 
Table 4: Statistical analysis of total nasal airway volume of the cleft side between both groups postoperatively

\begin{tabular}{lccc}
\hline & & Nasal airway volume & \\
\hline Pre-operative (cleft side) & Mean \pm S.D & Min -Max & T \\
Group I & $6394.25 \pm 448.89$ & $5528.23-7149.34$ & 0.582 \\
Group II & $6542.76 \pm 549.02$ & $5820.93-7371.89$ & 0.568 \\
& & & \\
Group I & & One year postoperative (cleft side) & \\
Group II & $7271.31 \pm 374.99$ & $6750.23-7875.49$ & \\
\hline
\end{tabular}

Table 5: Statistical analysis of septal deviation at ANS, midpoint and PNS between both groups postoperatively

\begin{tabular}{|c|c|c|c|c|}
\hline \multicolumn{5}{|c|}{ Septal deviation } \\
\hline Pre-operative & Group I & Group II & $\mathrm{t}$ & p-value \\
\hline ANS & $4.94 \pm 0.71$ & $4.38 \pm 1.53$ & 0.994 & 0.334 \\
\hline Mipoint & $5.53 \pm 0.967$ & $5.66 \pm 0.702$ & 0.344 & 0.735 \\
\hline PNS & $7 \pm 1.04$ & $7.11 \pm 0.576$ & 0.293 & 0.773 \\
\hline \multicolumn{5}{|c|}{ One year postoperative } \\
\hline ANS & $2.79 \pm 0.589$ & $2.69 \pm 0.668$ & 0.355 & 0.727 \\
\hline Midpoint & $5.09 \pm 0.968$ & $4.77 \pm 0.74$ & 0.831 & 0.417 \\
\hline PNS & $7 \pm 1.04$ & $7.10 \pm 0.576$ & 0.266 & 0.793 \\
\hline
\end{tabular}

\section{DISCUSSION}

Patients with nasal deformity secondary to CL\&P present an aesthetic and functional impairment leading to a psychological conflict which causes isolation and social exclusion in some cases ${ }^{[22,23]}$.

Although primary rhinoplasty is now commonly performed at the time of cheiloplasty, definitive rhinoplasty is recommended after the completion of facial skeletal growth to correct a remnant secondary cleft lip nasal deformity ${ }^{[24]}$.

Alveolar cleft grafting provides certain bony support for the nose and is thought to be beneficial for secondary cleft nasal deformity correction. Positive effects of bone graft on facial or nasal symmetry have been shown by Craven et al, 2007 $7^{[25]}$ and Nagasao et al, 2009 ${ }^{[9]}$.
In this study, late secondary alveolar bone grafting was performed because large number of cleft lip and palate patients missed the alveolar cleft grafting procedure during the long course of treatment and rehabilitation of the cleft deformities either simultaneously or six months before rhinoplasty.

An autogenous corticocancellous bone block and additional cancellous bone graft were obtained from mandibular symphysis in all cases except case no.4, group I obtained from anterior iliac crest, shaped according to the defect, extended to the pyriform margin for peri-alar augmentation and fitted snugly with additional cancellous bone was compressed around it to fill the defect except in cases no. 1 and no. 2, group I the graft was needed to be fixed with mini plate and screws this was matched with Lee et al, 2009 ${ }^{[26]}$ Theologie-Lygidakis et al, 2014 ${ }^{[27]}$. 
Bone graft resorption occurred at the cleft site in case no. 4, group I, this is due to continuous purulent discharge from the nose, antibiotic therapy was given to overcome this complication, this was in agree with Wiedel et al, 2016 $6^{[28]}$.

Open approach for rhinoplasty was performed in all cases, as it offered adequate exposure with excellent control and management of the deformity, this in accordance to Nolst-Trenité, 2005 ${ }^{[21]}$.

The columellar strut and alar graft used, is an autogenous cartilaginous septal graft which considered the gold standard grafting material as it is available in the same operative field as reported by and Quatela and Pearson, 2009 [29], González-Melgar et al, 2013 ${ }^{[30]}$.

In this study, we used subjective assessment of nasal obstruction which is NOSE Scale preoperatively and postoperativly. There was a significant decrease in NOSE scores postoperatively in both groups which means improvement of nasal obstruction due to septoplasty procedure for taking cartilage graft and at same time correcting septal deviation which was coincided with Hussein, 2016 $6^{[31]}$ and Zhang et al, 2018 ${ }^{[32]}$.

Objective assessment of nasal obstruction was performed in this study through measurement of nasal airway volume and septal deviation from 3D imaging using $\mathrm{CBCT}$ and computer software. upper airway measurements with CBCT could be accurately achieved, quantified by segmentation of the image, allow construction of $3 \mathrm{D}$ virtual surface models to match the volumetric data and reliable to measure airway volume as concluded by Aboudara et al, 2003 $3^{[33]}$ and Ghoneima and Kula, 2013 ${ }^{[34]}$.

We observed that the nasal airway volume in the cleft side partially improved postoperatively at ANS and midpoint between ANS and PNS and not improved at PNS after nasal surgery in both groups. All patients in both groups suffering from septal deviation towards the cleft side preoperatively. This deviation decreased and improved with varying degrees postoperativly at ANS and midpoint between ANS and PNS. At the PNS the septal deviation is not improved as it is composed almost entirely of bone which was not alleviated with a standard cartilaginous septoplasty so nasal airway volume at this area was not improved, which was coincided by Friel et al, 2015 $5^{[20]}$.

In this study, patients have inferior turbinate hypertrophy on the opposite side of a deviated septum which play an important role in nasal airway dysfunction leading to incomplete improvement of nasal airway volume which was matched with Farmer and Eccles, 1990 ${ }^{[35]}$.

In the present study, it was observed that objective measurements of nasal function correlate to subjective nasal symptoms and clinical findings at nasal examination in UCLP patients which in accordance to Peroz et al, 2017 $7^{[36]}$.
For aesthetic evaluation of the nose in group I, decreased AIA and subsequently ala tip angle which increase nasal symmetry suggest elevation of the alar base in cleft side, this most propably due to combined effect of bone graft and medial movement of the lateral crus and nasal ala, during which soft tissue underlying the cleft-side alar base was compacted and became thicker, while in group II, after first stage which is the alveolar cleft grafting the AIA and ala tip angle were decreased which suggest that alveolar cleft grafting had a significant direct effect on elevation of the alar base in cleft side and were increased again after six months of grafting which may be due to partial graft resorption. After second stage of rhinoplasty, the AIA and ala tip angle more decreased due to the additional effect of medial movement of the lateral crus and nasal ala, this was in agree with $\mathrm{Li}$ and Liu, 2011 ${ }^{[37]}$ who reported that the alveolar cleft grafting when performed in combination with nasal surgery, the bone graft effect on nasal symmetry would be camouflaged by adjustment of covering tissue. There was no significant difference between both groups in improvement of AIA and ala tip angle.

In this study, there was a significant improvement in NLA in both groups which in agreement with the findings of Gassling et al, 2015[38] and Hussein, 2016 $6^{[31]}$ which means that columellar struts offers sufficient axial and transversal stability against the soft tissue tension towards the columellar and cleft side nasal base.

There was a significant improvement of NFA which reflects the tip projection due to the fact that the columellar strut increased the columella show, the nasal projection, and the structural integrity of the tip support as stated by Pitak-Arnnop et al, 2011 ${ }^{[39]}$.

In this study, there was a decrease in the difference of alar base distance and the difference of the ala-tip angle between both sides for both groups with no significant difference between them which indicate symmetry in horizontal plane postoperatively this is parallel to the findings of Chaithanyaa et al, 2011 ${ }^{[17]}$ who reported in his study for evaluation of the outcomes of secondary rhinoplasty that all cases of cleft nasal deformity had a significant improvement in the facial aesthetics postoperatively.

In this study, the postoperative values of proportion indices of the upper lip are closer to 1 than the preoperative values in both groups which indicates improvement of upper lip symmetry. In group II, there was no effect of alveolar cleft grafting on the length of the upper lip which was inconsistent with Kim et al, 2012 ${ }^{[18]}$ who reported increase in the length of the upper lip.

For the evaluation of scar formation, we used the Patient and Observer Scar Assessment Scale (POSAS) and we noted in both groups that the overall patient score is lower than that of the observer, which means that patients were more satisfied with the appearance 
of the postoperative scarring which in accordance with Frans et al, 2012 $2^{[19]}$ and Asan et al, 2017[40] as they suggested that this is probably due to the fact that they still adapted to the pre-operative aspect and they confirm that patient opinion is the most important in scar evaluation.

\section{CONCLUSION}

Although there was no statistically significant differences clinically and radigraphically between one and two stages surgery of secondary cheilorhinoplasty and alveolar cleft grafting, however several factors are to be considered when going to select either of them as general health, psychological state and finance of the patient, schedule time of the patient for his life priorities and if he is travelling to an area of no availability of such services and time of the operation. Standardized photographs are efficient and can be used for aesthetic evaluation of the lip and nose. CBCT and usage of computer software are reliable tools for measuring nasal airway volume and septal deviation for assessment of nasal obstruction. NOSE scale is a reliable tool for evaluation of the nasal function. POSAS is an efficient tool for scar assessment. There was improvement in nasal function, nasal airway volume and septal deviation which were not complete due to inferior turbinate hypertrophy and bony septal deviation.

\section{CONFLICT OF INTEREST}

There are no conflicts of interests.

\section{REFERENCES}

1. Wang TD, Madorsky SJ. Secondary rhinoplasty in nasal deformity associated with the unilateral cleft lip. Arch Facial Plast Surg. 1999, 1: 40-5.

2. Shih CW, Sykes JM. Correction of the cleft-lip nasal deformity. Facial Plast Surg. 2002, 18: 253-62.

3. Hade DV, Peter JFML, eds. Textbook of Facial and Plastic Surgery, 2006: 305.

4. Nakamura N.: Surgical strategy for secondary correction of unilateral and bilateral cleft lip-nose deformities, Rhinoplasty, Dr.Michael Brenner, ed. 2011; ISBN:978-953-307-849-6.

5. Mahajan R, Ghildiyal H, Khasgiwala A, Muthukrishnan G, kahlon S. Evaluation of Secondary and Late Secondary Alveolar Bone Grafting on 66 Unilateral Cleft Lip and Palate Patients. Plastic Surgery. 2017, 25(3): 194-199.

6. Eskeland G, Bergland O, Borchgrevink H, Semb G, Abyholm FE. Management of the cleft alveolar arch. In: Jackson JT, Sommerlad BC, eds. Recent advances in plastic surgery 3 . Edinburgh: Churchill Livingstone, 1985; 13-32.
7. Bergland O, Semb G, Abyholm FE. Elimination of the residual alveolar cleft by secondary bone grafting and subsequent orthodontic treatment. Cleft Palate J. 1986, 23: 175-205.

8. Mokal NJ, Prabhash Kale C. Composite correction of a unilateral cleft lip nose deformity and alveolar bone grafting. Indian J Plast Surg. 2009, 42(1): S71-8.

9. Nagasao $T$, Ogata $H$, Miyamoto J, Jiang $H$, Kaneko T, Isshiki Y et al. Alveolar bone grafting for patients with unilateral complete alveolar and palatal clefts improves the bony structure of the nose. Cleft Palate Craniofac J. 2009, 46: 9-18.

10. Wu Y, Wang G, Yang Y, Zhang Y. Influence of alveolar-bone grafting on the nasal profile: unilateral cleft lips, alveoli, and palates. J Craniofac Surg. 2010, 21: 1904-7.

11. Kim YE, Han J, Baek RM, Kim BK. Alveolar bone grafting with simultaneous cleft lip rhinoplasty. Journal of Plastic, Reconstructive \& Aesthetic Surgery. 2016, 69(11): 1544-50.

12. Stewart MG., Witsell DL., Smith TL. Development and validation of the Nasal Obstruction Symptom Evaluation (NOSE) scale, Otolaryngol Head Neck Surg. 2004, 130: 157-63.

13. Ettorre G, Weber M, Schaaf H, Lowry JC, Mommaerts MY, Howaldt HP: Standards for digital photography in cranio-maxillofacial surgery-part I: basic views and guidelines. $\mathrm{J}$ of Cranio-Maxillofac Surg. 2006, 34: 65-73.

14. Li J., Liu B S. Aphotogrammetric study of the effects of alveolar bone grafting on nose symmetry among unilatral cleft patients.J of Plast, Reconstr and Aesthetic Surg. 2011, 64: 146-1443.

15. Anastassov GE, Joos U, Zollner B. Evaluation of the results of delayed rhinoplasty in cleft lip and palate patients. Functional and aesthetic implications and factors that affect successful nasal repair. British J of Oral and Maxillofac Surg. 1998, 36: 41-42.

16. Naini FB, Cobourne MT, Garagiola U , McDonald F, Wertheim D. Nasofacial angle and nasal prominence: A quantitative investigation of idealized and normative values. Journal of CranioMaxillo-Facial Surgery. 2016, 44: 446-452.

17. Chaithanyaa N., Shivakumar H.R., Upasi A. Evaluation of the out- come of secondary 
rhinoplasty in cleft lip and palate patients. J Plast Reconstr Aesthet Surg. 2011, 64: 27-33.

18. Kim SW, Park SO, Choi TH, Hai DT. Change in upper lip height and nostril sill after alveolar bone grafting in unilateral cleft lip alveolus patients. Journal of Plastic, Reconstructive \& Aesthetic Surgery. 2012, 65: 558-563.

19. Frans FA, van Zuijlen PM, Don Griot JP, vander Horst CM. Assessment of Scar Quality After Cleft Lip Closure. Cleft Palate-Craniofacial Journal. 2012, 49(2).

20. Friel MT., Starbuck JM., Ghoneima AM., Murage K, Kula KS., Tholpady S et al. Airway Obstruction and the Unilateral Cleft Lip and Palate Deformity Contributions by the Bony Septum. Ann Plast Surg. 2015, 75: 37-43.

21. Nolst-Trenité GJ. Basic approaches and techniques in nasal tip surgery. In: Nolst- Trenité GJ ed. Rhinoplasty $3^{\text {rd }}$ ed. The Hague: Kugler Publications, 2005: 87-96.

22. Bénateau H, Dine PA, Soubeyrand E, Vazquez MP, Picard A. Maxillary sequelae in cleft patients. Causes of maxillary hypoplasia and possible prevention. Rev Stomatol Chir Maxillo- fac. 2007, 108: 297-300.

23. Mani MR, Reiser E, Andlin-Sobocki A, Skoog V, Holm- strom M. Factors related to quality of life and satisfaction with nasal appearance in patients treated for unilateral cleft lip and palate. Cleft Palate Craniofac J. 2013, 50: 432-9.

24. Byrd HS, El-Musa KA, Yazdani A. Definitive repair of the unilateral cleft lip nasal deformity. Plast Reconstr Surg. 2007, 120: 1348-56.

25. Craven C, Cole P, Hollier L Jr, Stal S. Ensuring success in alveolar bone grafting: a threedimensional approach. J Craniofac Surg. 2007, 18: 855-859.

26. Lee C, Nishihara K, Okawachi T, Iwashita Y, Majima HJ, Nakamura N. A quantitative radiological assessment of outcomes of autogenous bone graft combined with platelet-rich plasma in the alveolar cleft. Int J Oral Maxillofac Surg. 2009, 38: 117-125.

27. Theologie-Lygidakis N, Chatzidimitriou K, Tzerbos F, Kolomvos N, Iatrou I. Development of surgical techniques of secondary osteoplasty in cleft patients following 12 years' experience. Journal of Cranio-Maxillo-Facial Surgery. 2014, 42: 839-845.

28. Wiedel A-P, Svensson H, Scho"nmeyr B, Becker M. An analysis of complications in secondary bone grafting in patients with unilateral complete cleft lip and palate. J Plast Surg Hand Surg. 2016, 50: 63-67.

29. Quatela VC, Pearson JM. Management of the aging nose. Facial Plast Surg. 2009, 25: 215-221.

30. González-Melgar S, Martín-Martín C Analysis and Treatment of Cleft Lip Nasal and Palate Deformity. Acta Otorrinolaringol Esp. 2013, 64(5): 323-330.

31. Hussein MAM, Sadakah AA, Beder RR. Evaluation of simultaneous secondary cheilorhinoplasty and alveolar bone grafting, Master thesis, Faculty of dentistry, Tanta university, Egypt, 2016.

32. Zhang L, Bai X, Li Z, Liu Q, Yang M, Wang $\mathrm{X}$ et al. Improvement of Aesthetic and Nasal Airway in Patients with Cleft Lip Nasal Deformities: Rhinoplasty with Septal Cartilage Graft and Septoplasty. The Cleft PalateCraniofacial Journal. 2018, 55(4): 554-561.

33. Aboudara CA, Hatcher D, Nielsen IL, Miller A. A three-dimensional evaluation of the upper airway in adolescents. Orthod Craniofac Res. 2003, 6(1): 173-5.

34. Ghoneima A, Kula K. Accuracy and reliability of cone-beam computed tomography for airway volume analysis. Eur J Orthod. 2013, 35: 256-61.

35. Farmer S, Eccles R.. Chronic inferior turbinate enlargement and the implications for surgical intervention. Rhinology. 1990, 4: 234-238.

36. Peroz R, Holmstro“m M, Mani M. Can objective measurements of the nasal form and function represent the clinical picture in unilateral cleft lip and palate? Journal of Plastic, Reconstructive \& Aesthetic Surgery. 2017, 70: 653-658.

37. Li J., Liu B S. Aphotogrammetric study of the effects of alveolar bone grafting on nose symmetry among unilatral cleft patients.J of Plast, Reconstr and Aesthetic Surg. 2011, 64: 146-1443. 
38. Gassling V, Koosb B, Birkenfelda F, Wiltfanga J, Zimmermann CE. Secondary cleft nose rhinoplasty: Subjective and objective outcome evaluation. Journal of Cranio-Maxillo-Facial Surgery. 2015, 43: 1855-1862

39. Pitak-Arnnop P, Hemprich A, Dhanuthai K, Yildirim V, Pausch NC. Panel and patient perceptions of nasal aesthetics after secondary cleft rhinoplasty with versus without columellar grafting. J Craniomaxillofac Surg. 2011, 39: 319-325.

40. Asan A, Tica C, Şapte E. The Value of the Posas Questionnaire in Assessing Postoperative Scarring of Patients with Cleft Lip. Clinical Anatomy Vol. 2017, XVI (4). 